\title{
Coulisses
}

Revue de théâtre

\section{Les compagnies professionnelles}

\section{A. Benichou et Rédaction}

\section{OpenEdition}

\section{Journals}

Édition électronique

URL : http://journals.openedition.org/coulisses/1624

DOI : $10.4000 /$ coulisses. 1624

ISSN : 2546-9460

\section{Éditeur}

Presses universitaires de Franche-Comté

\section{Édition imprimée}

Date de publication : 1 février 1991

Pagination : $12-13$

ISSN : 1150-594X

\section{Référence électronique}

A. Benichou et Rédaction, «Les compagnies professionnelles », Coulisses [En ligne], 3 | Hiver 1991, mis en ligne le 04 juillet 2017, consulté le 26 octobre 2019. URL : http://journals.openedition.org/coulisses/ 1624 ; DOI : 10.4000/coulisses. 1624

Ce document a été généré automatiquement le 26 octobre 2019

Coulisses 


\title{
Les compagnies professionnelles
}

\author{
A. Benichou et Rédaction
} dans ce domaine là mais c'était resté sur le plan du verbe, alors que j'espérais bien que ça déboucherait sur certains exercices qui touchent un peu tout ce qui est inconscient, impalpable. Ce travail que je vais faire ne s'adresse pas forcement à des acteurs mais à des êtres humains. Je crois que la notion de risque est très importante, c'est-à-dire que moi je prends un risque en venant ici et je voudrais que les gens qui assistent à cet atelier le prennent aussi.

5 Je tiens à dire tout le bien que je pense de Y. Thoret qui est vraiment un personnage merveilleux. C'est un des rares psychiatres que je connaisse qui manipule l'humour de façon extraordinaire, il en aborde la psychanalyse comme on rentre dans une pièce.

$6 \quad$ En tant que comédien pouvez-vous nous parler un peu votre parcours et du TPJ?

7 J'ai été formé au CDE - Centre dramatique de l'Est - à Strasbourg qui est devenu TNS.

8 J'ai ensuite travaillé avec beaucoup de gens et j'ai créé le TPJ en 1967. On fait un travail de création, d'animation, de travail d'été, on n'arrête pas! On fait toujours ce que j'appelle un travail de l'ombre, c'est-à-dire un travail qui ne se voit pas beaucoup. J'ai été envoyé en classe par le ministère des Affaires culturelles pour mener une action de décentralisation... je suis un pur enfant de la décentralisation! 


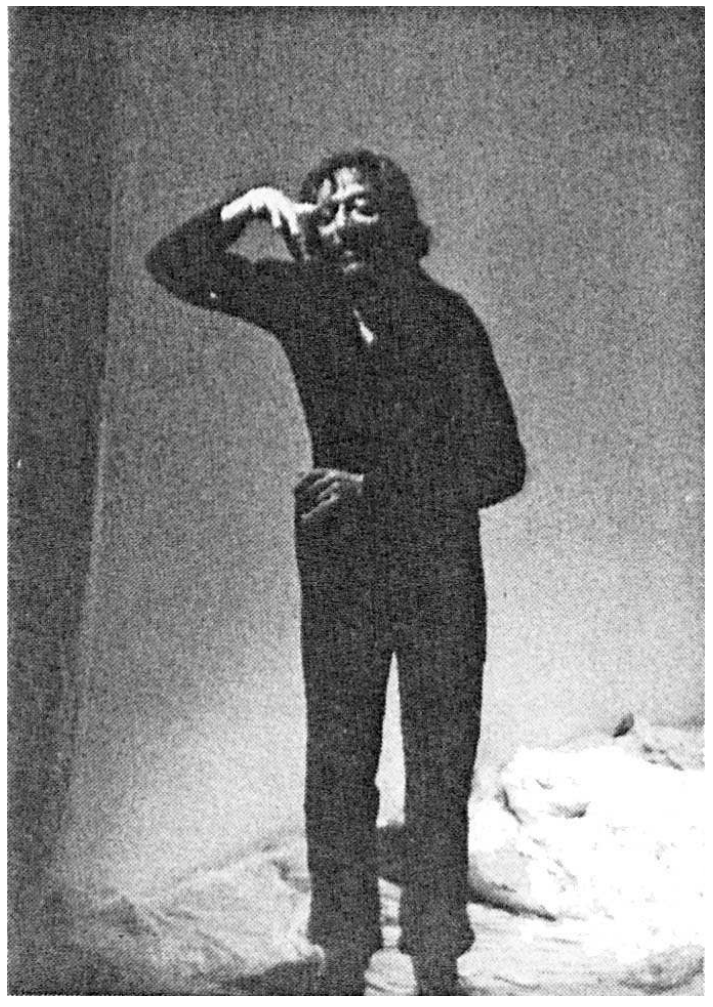

Pourquoi un one man show?

C'est une espèce de pari vous savez. Tout comédien, à un moment ou à un autre a envie de faire un one man show. Et puis on commence quand on a 213 ans de métier, on se rend compte que ce n'est pas possible, quand on a 10 ans de métier, on se rend compte encore que ce n'est pas possible! Moi, il a fallu que j'attende une vingtaine d'années pour monter ce spectacle.

Depuis quand avez-vous créé ce " ONE MAN CAUSE »?

12 C'est un spectacle que j'ai en main depuis cinq ans. Au départ, j'ai été aidé par un metteur en scène et c'était un spectacle très riche avec plein de choses qui se passaient sous le plateau : des comédiens me passaient des «trucs »... mais il fallait un jour et demi de montage et cela augmentait le prix du spectacle ainsi que le temps d'occupation des salles. Maintenant, il n'a plus rien à voir avec ce qu'il était... Au bout de la centième représentation, j'ai arrêté de compter !

Et vous ne vous en lassez pas?

14 Ah non, pas du tout! C'est un spectacle très demandé car il est très mobile, il y a trois fois rien. J'arrive le matin avec ma caisse, je monte, je mange, je joue. Je n'ai même pas un régisseur avec moi! J'ai monté ce spectacle car on m'a souvent demandé un spectacle mobile : monter le matin et jouer le soir, et comme on me le demande, je joue le plus souvent possible! Il m'est arrivé de le jouer trois fois par jour : le matin pour le collège, l'après-midi pour le lycée et le soir pour les adultes.

15 Le spectacle est basé sur la performance de l'acteur et sur des textes de littérature française et étrangère. Ce sont tous les textes qui ont fait «tilt» chez moi, qui ont changé ma direction de vie. C'est comme ça que j'ai au départ choisi ces textes, et puis j'avais cinq heures de spectacle ! Alors, j'ai coupé... j'ai tenu beaucoup à ce que ça ne fasse pas des textes alignés les uns à côté des autres car il faut qu'un spectacle raconte 
une histoire. C'est donc un spectacle d'une heure et demie et ce n'est pas des textes dits, sur le plan du travail... c'est vraiment un spectacle.

Quelles sont vos références littéraires?

17 Le premier texte sur le spermatozoïde est un texte de Rissey Bariet, ensuite il y a Dario Fo, Le Nez de Gogol, Michaux, La Chevelure de Maupassant, Plume au restaurant de Pichette - vous savez, tous les textes de vingt ans, trente ans ou quarante ans - une phrase de P. Handke que j'aime beaucoup et je termine par un texte de Georges Perec extrait de La Vie mode d'emploi.

18 Et quels sont vos projets?

19 Je viens de monter une pièce d'un auteur qui se nomme Jean-Jacques Varouyan et elle vient d'être achetée par le TPJ, on va donc la monter la saison prochaine. Et puis, je vais monter Tartuffe à la rentrée prochaine. Et là, en ce moment, je joue Le Cid à Strasbourg.

\section{NOTES}

1. Yves Thoret a écrit un article " Freud et le théâtre ", Coulisses n ${ }^{\circ} 1$.

\section{AUTEURS}

\section{A. BENICHOU}

Directeur du TPJ, conseiller technique et pédagogique 